\title{
Precipitation Variability in West Africa in the Context of Global Warming and Adaptation Recommendations
}

\author{
Gandome Mayeul L. D. Quenum, Nana A. B. Klutse, Eric A. Alamou, \\ Emmanuel A. Lawin, and Philip G. Oguntunde
}

\section{Contents}

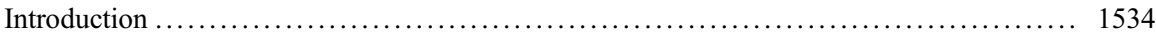

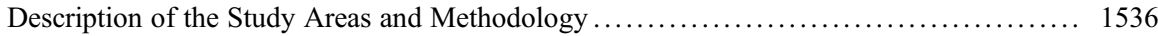

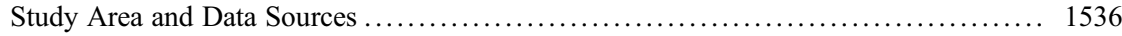

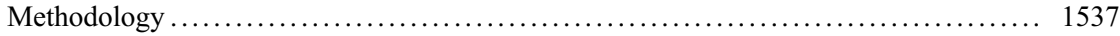

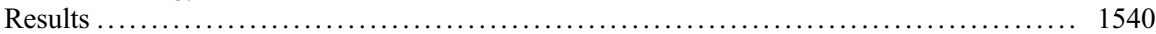

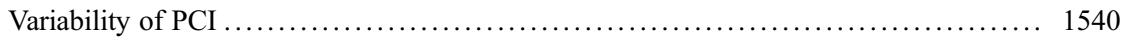

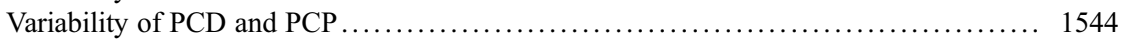

Daily Precipitation Variability ........................................... 1544

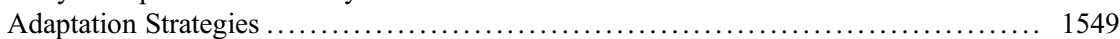

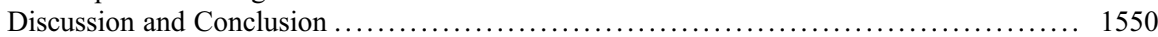

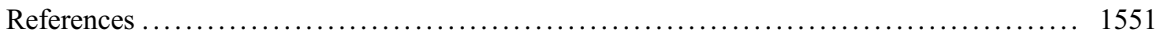

This chapter was previously published non-open access with exclusive rights reserved by the Publisher. It has been changed retrospectively to open access under a CC BY 4.0 license and the copyright holder is "The Author(s)". For further details, please see the license information at the end of the chapter.

G. M. L. D. Quenum (殴)

West African Science Service Centre for Climate Change and Adapted Land Use (WASCAL)

Graduate Research Program in West African Climate System (GRP-WACS), Federal University of Technology, Akure (FUTA), Akure, Nigeria

Laboratory of Applied Hydrology (LHA), National Institute of Water (NIW), Cotonou, Bénin e-mail: malgdaq2000@yahoo.fr

N. A. B. Klutse

Ghana Space Science and Technology Institute, Atomic Energy Commission, Accra, Ghana

E. A. Alamou · E. A. Lawin

Laboratory of Applied Hydrology (LHA), National Institute of Water (NIW), Cotonou, Bénin

P. G. Oguntunde

Department of Agricultural and Environmental Engineering, Federal University of Technology,

Akure, Nigeria

W. Leal Filho et al. (eds.), African Handbook of Climate Change Adaptation, https://doi.org/10.1007/978-3-030-45106-6_85 


\section{Abstract}

It is commonly accepted that the Earth's climate is changing and will continue to change in the future. Rising temperatures are one of the direct indicators of global climate change. To investigate how the rising global temperature will affect the spatial pattern of rainfall in West Africa, the precipitation and potential evapotranspiration variables from ten Global Climate Models (GCMs) under the RCP8.5 scenario were driven by the Rossby Centre regional atmospheric model (RCA4) from the COordinated Regional Climate Downscaling EXperiment (CORDEX) and analyzed at four specific global warming levels (GWLs) (i.e., $1.5{ }^{\circ} \mathrm{C}, 2.0^{\circ} \mathrm{C}, 2.5^{\circ} \mathrm{C}$, and $3.0^{\circ} \mathrm{C}$ ) above the preindustrial level. This study utilized three indices, the precipitation concentration index (PCI), the precipitation concentration degree (PCD), and the precipitation concentration period (PCP) over West Africa to explore the spatiotemporal variations in the characteristics of precipitation concentrations. Besides, the analysis of the effect of the specified GWLs on the Consecutive Dry Days (CDD), Consecutive Wet Days (CWD), and frequency of the intense rainfall events allowed to a better understanding of the spatial and temporal patterns of extreme precipitation in West Africa. Results reveal that, for the projections simulations and at each GWL, the rainfall onset starts one month earlier in the Gulf of Guinea in response to the control period. To encourage adaptation to the various changes in climate in general, and particularly in respect of rainfall, this study proposes several adaptation methods that can be implemented at the local (country) level, as well as some mitigation and adaptation strategies at the regional (West African) level.

\section{Keywords}

Precipitation concentration index (PCI) - Precipitation concentration degree $(\mathrm{PCD}) \cdot$ Precipitation concentration period $(\mathrm{PCP}) \cdot$ Adaptation strategy $\cdot$ Global warming

\section{Introduction}

Precipitation variability and concentration are two important climate factors with an impact on society, agriculture, and the environment, as increased precipitation variability can reduce agricultural yields (Rowhani et al. 2011). Also, precipitation variability is strongly connected to extreme wet and dry events, floods, and droughts, which pose threats to the environment and to society, and can also have devastating consequences on ecosystems, food supplies, and economies at the local, regional, and global scale (Easterling et al. 2000). In its 5th report, the Intergovernmental Panel on Climate Change (IPCC) stresses that there is an increase in the number of extreme weather events for the twenty first century due to climate change (IPCC 2014). As temperatures rise, the amount of water vapor in the atmosphere also increases and the spatiotemporal distributions of precipitation change, resulting in significant differences in precipitation across the world (Chou and Lan 2011; 
Gao et al. 2014). Obtaining real-time information and facilitating earlier predictions by decision makers can be an efficient tool to adapt and to mitigate the impacts of climate events. However, this is an especially challenging task over data-sparse regions as West Africa, where unreliable monitoring networks and generally low institutional capacity limits the spread of timely information (Sheffield et al. 2014).

To assess the spatial and temporal variability of precipitation, various methods were adopted and documented. Precipitation concentration plays an important role, firstly, with regard to the annual total precipitation amount days and, secondly, with regard to the time and degree of concentration of the yearly total precipitation within a year. This variable has the potential to cause floods and drought events, both of which are expected to put considerable pressure on water resources (Zhang and Qian 2003; Zhang et al. 2009). Several studies have been interested in the importance of precipitation concentration indices. The present study adopted three of them: (i) the precipitation concentration index (PCI), which was developed by Oliver (1980); and years after was modified by De Luis et al. (2011). It has been used by Shi et al. (2015) as an indicator of the rainfall concentration for annual and seasonal scales, and Ezenwaji et al. (2017) to investigate the implications of the concentration and variability of rainfall on flooding over Awka Urban Area (Nigeria). (ii) The precipitation concentration degree (PCD) and (iii) the precipitation concentration period (PCP), which were redefined by Zhang and Qian (2003) in a study of droughts and floods in the Yangtze River valley (China). The basic concept behind the PCD and PCP is that the monthly total precipitation is a vector quantity with both magnitude and direction (Li et al. 2011; Wang et al. 2013).

In order to investigate and understand future climates, scientists refer to climate scenarios to provide a plausible explanation of how the future may evolve with respect to a number of variables, including socioeconomic change, technological change, energy and land-use, and the emissions of greenhouse gasses (GHGs) and air pollutants (Van Vuuren et al. 2011). Many factors are taken into account in order to predict how future global warming will contribute to climate change. A key variable is future GHG emissions. Some studies over West Africa (e.g., Egbebiyi 2016; Haensler et al. 2013; Sylla et al. 2012) have shown that projected increases in global GHG concentrations will lead to an increase in the frequency and intensity of extreme rainfall events (Klutse et al. 2018). So, for the meeting by the Intergovernmental Panel on Climate Change (IPCC) in 2007, four RCP radiative forcing levels were retained (Moss et al. 2008). The Representative Concentration Pathway (RCP) is defined as the trajectories relating to GHG concentrations, and was projected by the IPCC in 2014. The four Representative Concentration Pathways (RCPs), namely, RCP2.6, RCP4.5, RCP6, and RCP8.5, are labeled after a possible range of radiative forcing values up to the year $2100\left(2.6,4.5,6.0\right.$, and $8.5 \mathrm{~W} / \mathrm{m}^{2}$, respectively).

In 2010, the sixteenth session of the Conference of the Parties (COP16) adopted the Cancun Agreement for keeping the global temperature rise below $2.0{ }^{\circ} \mathrm{C}$ (UNFCCC 2010). A few years later, in 2015, at Paris, the COP21 proposed an ambitious target, which is to keep the increase in global average temperature to well below $2.0^{\circ} \mathrm{C}$ above preindustrial levels, while pursuing efforts to limit the temperature increase to $1.5{ }^{\circ} \mathrm{C}$. The rate of climate change is an important issue for mitigation and/or adaptation policies (Watkiss et al. 2015). Many studies have 
recently examined regional risks for the whole of Africa, as well some of its regions, such as Southern Africa and West Africa, at various global warming levels (GWLs). Recently, Déqué et al. (2017) suggested a classification of global warming for all the RCPs and for GWLs from $1.5^{\circ} \mathrm{C}$ to $4{ }^{\circ} \mathrm{C}$. Based on Déqué et al.'s (2017) suggestion, several studies (Abiodun et al. 2019; Klutse et al. 2018; Kumi and Abiodun 2018; Maúre et al. 2018; Nikulin et al. 2018) were done to assess the impact of different GWLs on various climate variables.

Mitigation and adaptation are two fundamental societal response options to deal with the problem of climate change (IPCC 2001; Füssel 2007; Locatelli 2011). The community of climate change scientists has focused mainly on mitigation rather than adaptation; for a long time, the latter has been ignored in the debate on climate change (Füssel 2007; De Perthuis et al. 2010). Mitigation policies have already been adopted at the international level, since it is clear that the global climate is already changing and will continue to change in the future due to anthropogenic GHG and aerosol emissions; it is thus important to make adjustments all the more urgently, especially at a local level (Füssel 2007; De Perthuis et al. 2010). In addition, though, there is a need to focus the debate on adaptation measures to climate change in order to prepare communities, especially the most vulnerable ones, to cope with its impacts (Kpadonou et al. 2012).

Identification of a suitable methodology to assess the spatiotemporal precipitation distribution is vital for planning effective adaptation and mitigation strategies to overcome potential drought and flood situations. Selecting the optimal methodology or tools may be useful for planning disaster management and preparedness to respond to droughts and floods, and to mitigate their effects on the activities in different sectors of the economy. Therefore, this study aims to use the analyses of PCI, PCD, PCP, consecutive dry days (CDD), and consecutive wet days (CWD) to explain the spatial and temporal variability of precipitation in West Africa in the context of GWLs $1.5^{\circ} \mathrm{C}, 2.0^{\circ} \mathrm{C}, 2.5^{\circ} \mathrm{C}$, and $3.0^{\circ} \mathrm{C}$.

\section{Description of the Study Areas and Methodology}

This section describes the study area and the data used (section "Study Area and Data Sources"), and the methodology that was applied (section "Methodology") to arrive at the results.

\section{Study Area and Data Sources}

The study area lies in West Africa, which is located between latitudes $00^{\circ} \mathrm{N}$ and $20^{\circ} \mathrm{N}$ and longitudes $20^{\circ} \mathrm{W}$ and $20^{\circ} \mathrm{E}$ (Fig. 1). This region is bordered in the South by the Gulf of Guinea, in the north by Mauritania, Mali, and Niger; the Cameroon highlands form the eastern boundary, while the Atlantic Ocean forms the western limit. The annual mean temperature is about $18{ }^{\circ} \mathrm{C}$, but the monthly mean can be more than $40{ }^{\circ} \mathrm{C}$ over the southern part of the Sahara. Rainfall patterns over this region are mostly affected by ocean currents and local features, such as topography. 


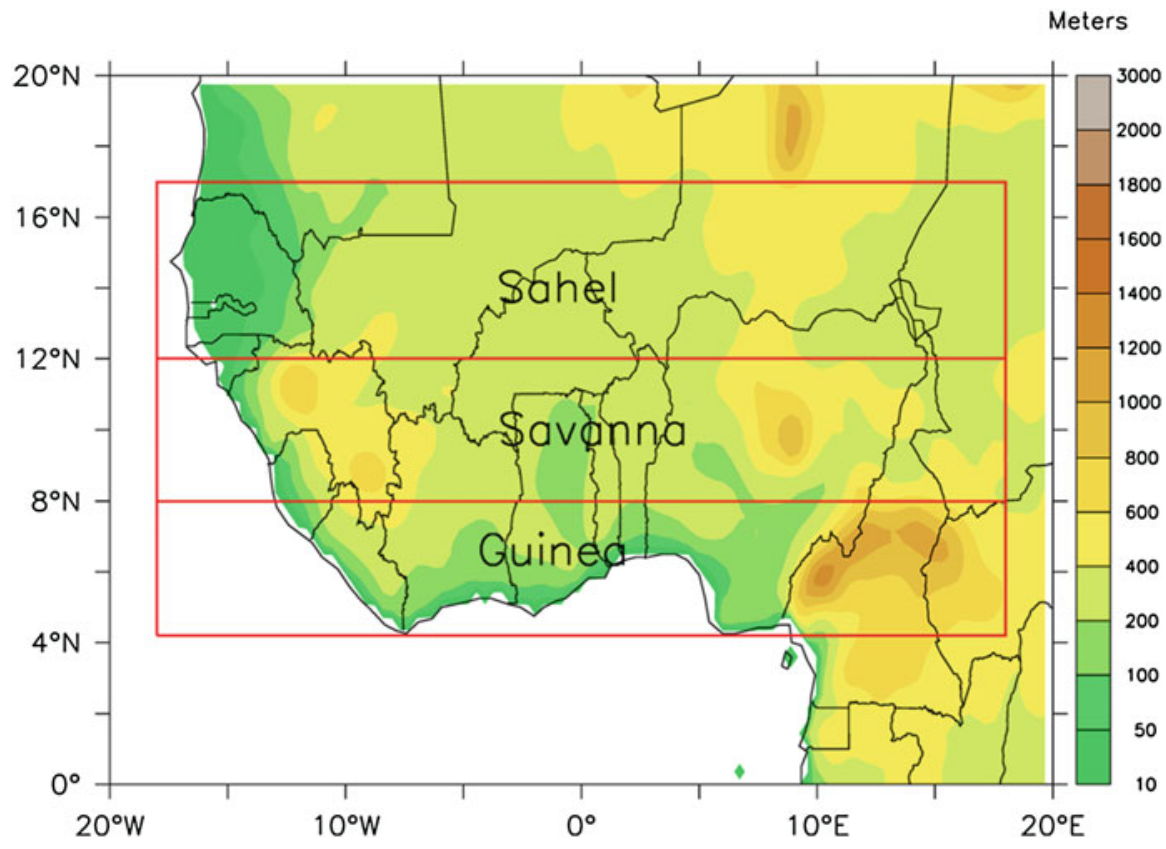

Fig. 1 Study domain showing the West African topography and the area of focus, which comprises the Gulf of Guinea (Guinea), the Savanna, and the Sahel zones (Diasso and Abiodun 2015)

In terms of climatic zones, West Africa can be divided into three different regions. The first region covers the Sahel and is characterized as a semiarid zone ranging from western Senegal to eastern Sudan, between $12^{\circ} \mathrm{N}$ and $20^{\circ} \mathrm{N}$. The second region is the Sudano-Sahelian zone, while the last and the third comprises the Guinea coast, which is characterized by a bimodal mode driven by the Intertropical discontinuity (ITD).

Precipitation and potential evapotranspiration variables from CORDEX are used in this study. Data from CORDEX are driven by RCA4 at daily and monthly timesteps. The simulated dataset used was collected from the coordinated regional climate downscaling experiment (CORDEX) (Nikulin et al. 2012), and has a horizontal resolution of $0.44^{\circ} \times 0.44^{\circ}$. The period of $1971-2000$ was extracted from the simulated dataset as the historical period, while the period of 2006-2100 was used for projections. This study focuses specifically on the GWLs of $1.5{ }^{\circ} \mathrm{C}, 2.0{ }^{\circ} \mathrm{C}$, $2.5^{\circ} \mathrm{C}$, and $3.0^{\circ} \mathrm{C}$ above the preindustrial levels and under the RCP8.5 scenario. The 30 -year projection according to each GWL can be found in Table 1.

\section{Methodology}

The PCI is calculated in the section "Calculation of Precipitation Concentration Index (PCI)" to classify how the rainfall is spatially distributed, and the PCD and PCP in the section "Computation of Precipitation Concentration Degree (PCD) and Precipitation 
Table 1 Recapitulative of the selected years for the ten GCMs drove by RCA4 model according to each global warming level. (Adapted by Quenum et al. 2019 from Déqué et al. 2017)

\begin{tabular}{l|l|l|l|l|l}
\hline \multicolumn{5}{l}{} & \multicolumn{5}{l}{} \\
\hline RCM & GCM & $1.5{ }^{\circ} \mathrm{C}$ & $2.0{ }^{\circ} \mathrm{C}$ & $2.5{ }^{\circ} \mathrm{C}$ & $3.0^{\circ} \mathrm{C}$ \\
\hline \multirow{2}{*}{ RCA4 } & CanESM2 & $1999-2028$ & $2012-2041$ & $2024-2053$ & $2034-2063$ \\
\cline { 2 - 6 } & CNRM-CM5 & $2015-2044$ & $2029-2058$ & $2041-2070$ & $2052-2081$ \\
\cline { 2 - 6 } & CSIRO-Mk3 & $2018-2047$ & $2030-2059$ & $2040-2069$ & $2050-2079$ \\
\cline { 2 - 6 } & EC-EARTH-r12 & $2005-2034$ & $2021-2050$ & $2034-2063$ & $2047-2076$ \\
\cline { 2 - 6 } & GFDL-ESM2M & $2020-2049$ & $2037-2066$ & $2052-2081$ & $2066-2095$ \\
\cline { 2 - 6 } & HadGEM2-ES & $2010-2039$ & $2023-2052$ & $2033-2062$ & $2042-2071$ \\
\cline { 2 - 6 } & IPSL-CM5A-MR & $2002-2031$ & $2016-2045$ & $2027-2056$ & $2036-2065$ \\
\cline { 2 - 6 } & MIROC5 & $2019-2048$ & $2034-2063$ & $2047-2076$ & $2058-2087$ \\
\cline { 2 - 6 } & MPI-ESM-LR & $2004-2033$ & $2021-2050$ & $2034-2063$ & $2059-2088$ \\
\cline { 2 - 6 } & NorESM1-M & $2019-2048$ & $2034-2063$ & $2047-2076$ & $2059-2088$ \\
\hline
\end{tabular}

Concentration Period (PCP)" were designed to determine, respectively, the period (months) and the degree of the concentration of the precipitation during the year.

\section{Calculation of Precipitation Concentration Index (PCI)}

The PCI, which was developed by Oliver (1980), modified by De Luis et al. (2011) and also used by Shi et al. (2015), was used as an indicator of rainfall concentration for annual and seasonal scales (wet and dry seasons). In our study, the PCI was tested to identify future trends in respect of the spatial distribution of rainfall. According to Oliver (1980), PCI values of less than 10 represent a uniform precipitation distribution (i.e., a low precipitation concentration), values between 11 and 15 denote a moderate precipitation concentration, values from 16 to 20 denote an irregular distribution, and values above 20 represent a strong irregularity of precipitation distribution (i.e., a high precipitation concentration). The following equations were used on each grid point to calculate the PCIs:

$$
\begin{aligned}
\mathrm{PCI}_{\text {annual }} & =\frac{\sum_{i=1}^{12} P_{i}^{2}}{\left(\sum_{i=1}^{12} P_{i}\right)^{2}} \times 100 \\
\mathrm{PCI}_{\mathrm{wet}} & =\frac{\sum_{i=1}^{n w} P_{i}^{2}}{\left(\sum_{i=1}^{n w} P_{i}\right)^{2}} \times \frac{100 * n w}{12} \\
\mathrm{PCI}_{\mathrm{dry}} & =\frac{\sum_{i=1}^{n d} P_{i}^{2}}{\left(\sum_{i=1}^{n d} P_{i}\right)^{2}} \times \frac{100 * n d}{12}
\end{aligned}
$$


Equation 1 was used for annual PCI, while Equations 2 and 3 were utilized for seasonal scales (rainy and dry seasons, respectively); $n w$ and $n d$ represent, respectively, the number of rainy and dry season months, and $P=$ precipitation of the $i^{\text {th }}$ month. In order to investigate changes in the PCI, a 30-year period was considered both for historical and future periods. Table 1 shows the projection periods used for each GWL; the historical 30-year period is 1971-2000.

\section{Computation of Precipitation Concentration Degree (PCD) and Precipitation Concentration Period (PCP)}

The PCD and PCP were proposed by Zhang and Qian (2003) to measure the distribution of rainfall and the peak of its concentration date. The basic principle is based on the vector of daily or monthly total precipitation. The assumption can be made that at a time scale (daily, 5-day, weekly, decade or monthly) total precipitation is a vector quantity with both magnitude and direction and can be illustrated as a circle $\left(360^{\circ}\right)$. According to Li et al. (2011) and Zhang and Qian (2003), the indices were calculated as follows:

$$
\begin{gathered}
\theta_{j}=\left(360^{\circ} * \frac{j}{n}\right) \\
R_{i}=\sum r_{i j} \\
R_{x i}=\sum_{j=1}^{N} r_{i j} * \sin \theta_{j} \\
R_{y i}=\sum_{j=1}^{N} r_{i j} * \cos \theta_{j} \\
\operatorname{PCD}_{i}=\frac{\sqrt{R_{x i}^{2}+R_{y i}^{2}}}{R_{i}}
\end{gathered}
$$

where $i$ is the year (e.g., for the historical period $i=1971,1972, \ldots, 2000), j$ represents the time scale (daily, 5-day, weekly, decade, or monthly) of that year, $R_{i}$ is the amount of rainfall of a year, $r_{i j}$ is the precipitation of the $j^{\text {th }}$ time scale in the $i^{\text {th }}$ year, $n$ is the number of time scales per year (e.g., daily: for a non-leap year, $n=365$, while in a leap year, $n=366$ )

$$
\begin{gathered}
\alpha_{i}=\tan ^{-1}\left(\frac{R_{x i}}{R_{y i}}\right) \\
D_{i}=\left\{\begin{array}{c}
\alpha_{i}\left(R_{y i}>0, R_{x i} \geq 0\right) \\
\alpha_{i}\left(R_{y i}>0, R_{x i}<0\right) \\
\alpha_{i}\left(R_{x i}<0\right)
\end{array}\right. \\
\operatorname{PCP}_{i}=D_{i} *\left(\frac{n}{360^{\circ}}\right)
\end{gathered}
$$


The next section discusses the results obtained with regard to the three indices above mentioned.

\section{Results}

This section presents the results obtained from the study. Based on the variability between the historical period (1971-2000, also referred to as the control period, CTL) and the various GWLs periods the section "Annual Precipitation Concentration" shows the annual precipitation concentration patterns, while the section "Seasonal Precipitation Concentration" focuses on the seasonal PCI variabilities. The section "Evaluation of the Models' Robustness" investigates the robustness of the models to assess the PCI over West Africa. The period and the degree of the concentration of the rainfall are evaluated in the section "Variability of PCD and PCP", while the section "Daily Precipitation Variability" shows the daily consecutive precipitation variability. Finally, the adaptation processes proposed are explained in section "Adaptation Strategies."

\section{Variability of PCI}

The variability of the PCI is investigated in sections "Annual Precipitation Concentration" and "Seasonal Precipitation Concentration," respectively, for the annual and seasonal time scales.

\section{Annual Precipitation Concentration}

The variability of the PCI computed across West Africa at an annual scale is between 12 and above 20 (Fig. 2a-e). According to a classification established by Oliver (1980), this high variability of the PCI values over West Africa illustrates the existence of a seasonal rainfall regime. Lower values (between 12 and 13) are noticed for the simulation of the historical period over the Gulf of Guinea, which means that this region of the study domain has a moderate precipitation concentration when interested in the distribution at the annual scale. The seasonality is more pronounced in the Savanna with PCI range between 17 and 18 (according to Oliver's (1980), this explains how the precipitation is irregularly distributed both spatially and temporally). Lastly, the Sahel region recorded a high precipitation concentration (PCI $>20$ ), which means that the precipitation is strongly irregularly distributed. For the specified GWLs, it is illustrated in Fig. 2a-e that for the Gulf of Guinea and the Savanna, the precipitation concentration is irregularly distributed except for some countries like Côte d'Ivoire and Liberia which have a low PCI.

\section{Seasonal Precipitation Concentration}

There are two major seasons over the study area. For the purposes of this analysis, the rainy season is assumed to last from early May to the end of September (MJJAS). 

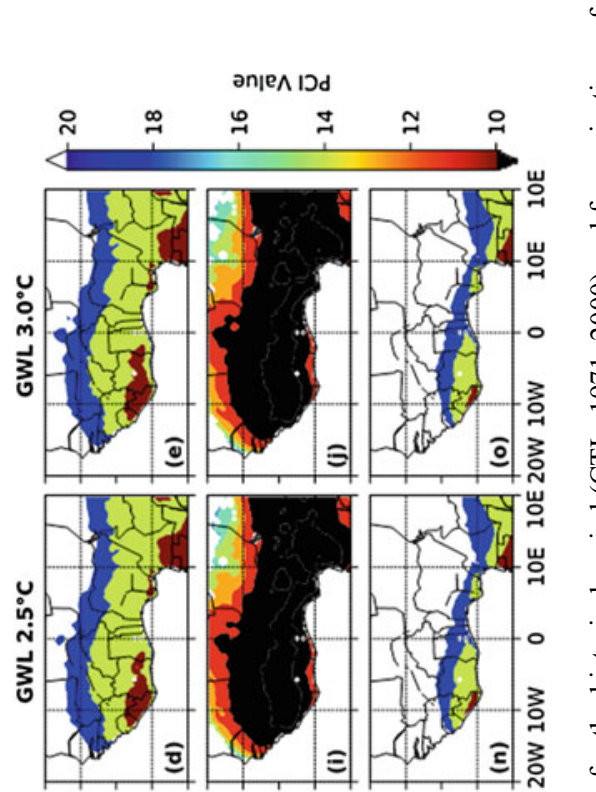

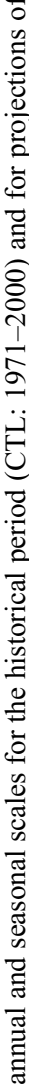
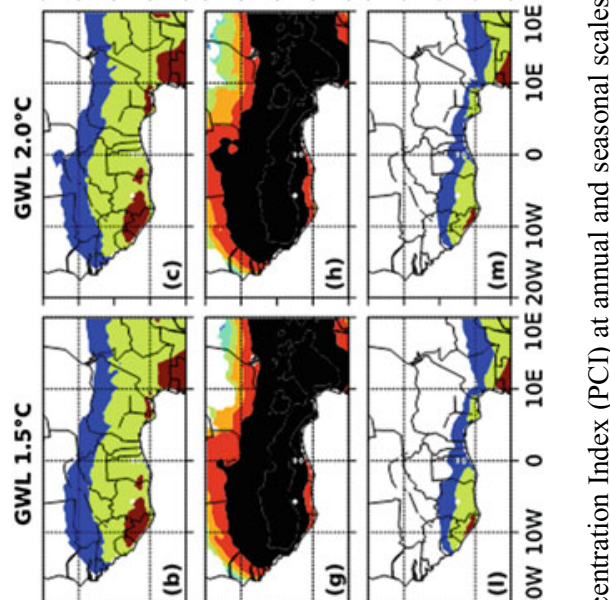

西
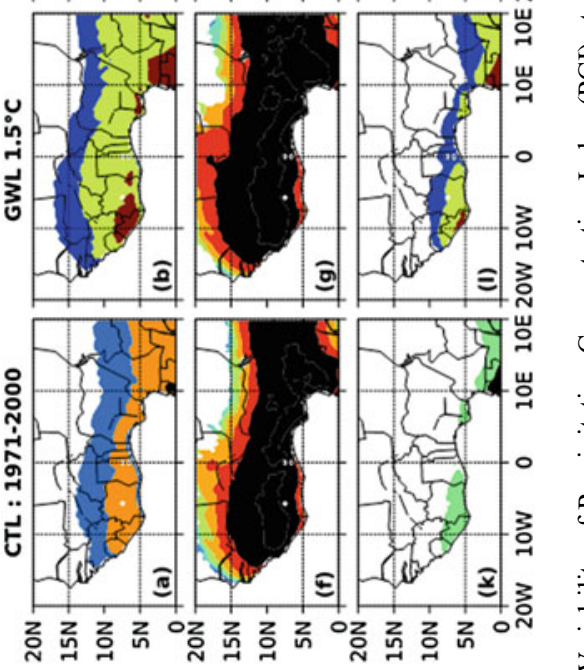

.

.

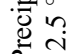

ก

곸울

要

jenuur uoseas-tom uoseas-ka $N$ क

章学 
The PCI computed for the seasonal scale over West Africa indicates complex spatial patterns of precipitation distribution. Therefore, Fig. $2 \mathrm{f}-\mathrm{j}$ shows that precipitation is uniformly distributed (i.e., almost the same amount of precipitation occurs in each month) over the Gulf of Guinea and the Savanna. For the studied GWLs, when compared with the historical period, it can be noticed that the uniform precipitation distribution extends a little toward the Sahel. So, the precipitation concentration is irregularly distributed (i.e., $P C I \in[16,20]$ according to Oliver 1980) over the northern region of West Africa during the rainy season.

Figure $2 \mathrm{k}-\mathrm{o}$ presents the PCI for the dry season. It illustrates an irregular precipitation concentration distribution over the Gulf of Guinea. This is obvious, because there is almost no rain during this period of the year, and the irregular distribution noticed might be due to some isolate rains recorded after some particular meteorological phenomena. The precipitation in the Savanna and Sahel is strongly irregularly distributed (i.e., $P C I>20$ during the rainy period, according to Oliver 1980), which means that the total of significant precipitation occurs within a short period (1-2 months).

The analysis of simulations presented in Fig. 2 (with regard to annual and seasonal evaluation) establishes that in West Africa, the precipitation is uniformly well distributed during the period May-September (MJJAS) in the Gulf of Guinea and the Savanna. A northward gradient is well noticed because the highest values of the PCI are located in the Sahel, whereas the lowest are identified around the Gulf of Guinea. Despite the global warming effect for all levels, the precipitation concentration does not change over the Gulf of Guinea and the Savanna; on the contrary, it extends toward the northern region of the study domain.

\section{Evaluation of the Models' Robustness}

Figure 3, which presents the differences between the projected PCI in respect of the historical period, shows that the level of variability is similar from one GWL to another. The annual and seasonal concentrations reduce gradually from the Sahel to the Gulf of Guinea, and confirm the variability illustrated by Fig. 2, which shows the regression of irregular and strong irregular precipitation concentrations. Figure 3 also illustrates the robustness of the simulations. At least $80 \%$ of models (indicated here with vertical green strips) demonstrate that the precipitation concentration over the eastern part of the study area has changed. This change, which increases according to the GWLs, is also shown over several countries, such as Niger during the rainy season. At least $80 \%$ of the models demonstrated that the change is significant (as indicated by the horizontal blue strips), with a confidence level of $95 \%$. Here too, Niger and Nigeria are projected to experience significant changes, which will increase with the GWLs. The red cross $(+)$ is observed in the area where at least $80 \%$ of the simulations agree with regard to the change, and where these changes have a $95 \%$ confidence level. Therefore, during the rainy season and under GWL3.0, countries such as Ghana, Togo, and Burkina Faso present a more uniform precipitation distribution, in contrast to variabilities for the historical period and the projections (Fig. 2). 


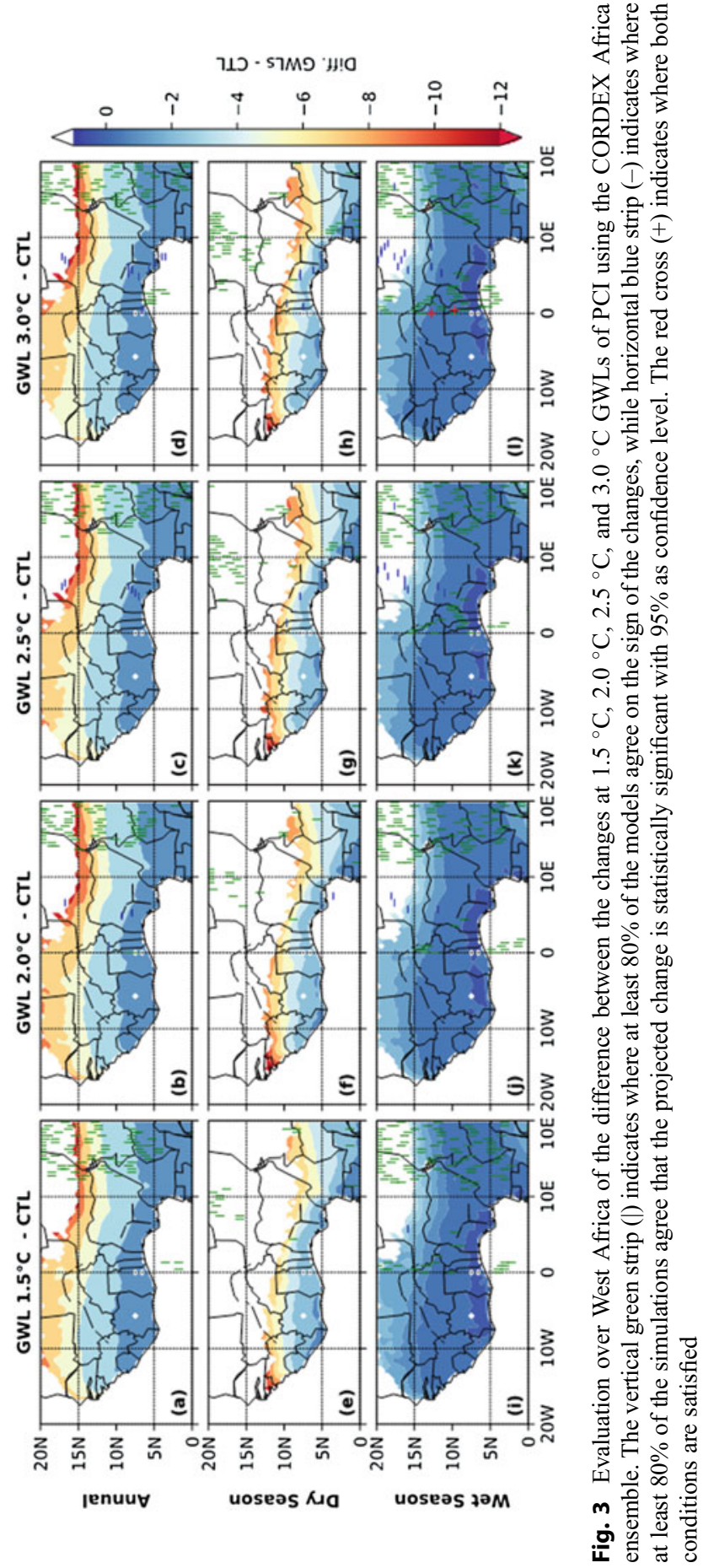




\section{Variability of PCD and PCP}

Figure 4 presents the PCP and PCD. Figure 4a-e shows that the variability over the entire West Africa of PCPs both for historical and projected periods is a range between $7 \pm 2$. This indicates that the yearly mean precipitation concentration over West Africa occurs between June and September. The analysis corroborates with the current knowledge about the period of the West African precipitation producing system, which is led by the West African Monsoon (WAM). The high values during the control period are observed in the north-western of West Africa, while regarding the projected period, the highest values are recorded over the Sahel. The finding indicates that the wet season starts earlier in the southern regions, followed by the Savanna before reaching the Sahel in the North. The variability of the yearly mean PCDs (shown in Fig. $4 \mathrm{f}-\mathrm{j}$ ) is between 0.17 and 0.90 , indicating the high spatial variability of the precipitation concentration in the study domain. When looking at the historical period simulations (Fig. 4f), it can be observed that the computed PCDs increase northwardly. Lower values $(0.17-0.60)$ are located around the Guinea coast, and the highest $(>0.80)$ in the Sahel. This denotes the existence of a gradient across the Gulf of Guinea and the Sahel. This gradient informs that precipitation during the rainy season is more concentrated in a few months across the Sahel compared to the Gulf of Guinea. For the projected simulations, the same gradient Gulf-of-Guinea-Sahel is observed, although here the magnitude of the PCD is less in response to the control period. The lower values lie between 0.17 and 0.50 , and the higher range between 0.5 and 0.6. During the projected period, there is globally a decrease of precipitation concentration compared to the historical period, leading both the Sahel and the Savanna having the same precipitation distribution for all GWLs studied. Furthermore, the projections indicate a shift in time for the starting of the rainy season. Therefore, comparing the projected and the present period, it is noticed that the wet season will state earlier. The highest concentration of precipitation will occur from May to July for the Gulf of Guinea and the Savanna, and in August for the Sahel.

\section{Daily Precipitation Variability}

The consecutive wet days (CWD) and consecutive dry days (CDD) were calculated over the study domain to evaluate the daily variability of the precipitation distribution. CWD and CDD also indicate extremes in rainfall. CDD is furthermore a useful indicator for studying short-term droughts (Frich et al. 2002) and drought tendencies (Orlowsky and Seneviratne 2012), as it could indicate enhanced dryness and high risk for seasonal droughts (Klutse et al. 2018). Changes in CDD and CWD can lead to uneven temporal distributions of rainfall, which could have a significant consequence for agricultural practices (Barron et al. 2003; FAO et al. 2015; Wiebe et al. 2017). The CDD was calculated both at annual (cdd) and seasonal scales (in this study, MaySeptember: MScdd), in order to evaluate both dry and wet spells within the rainfall season; knowing this is very important for agricultural practices in the region (Klutse 


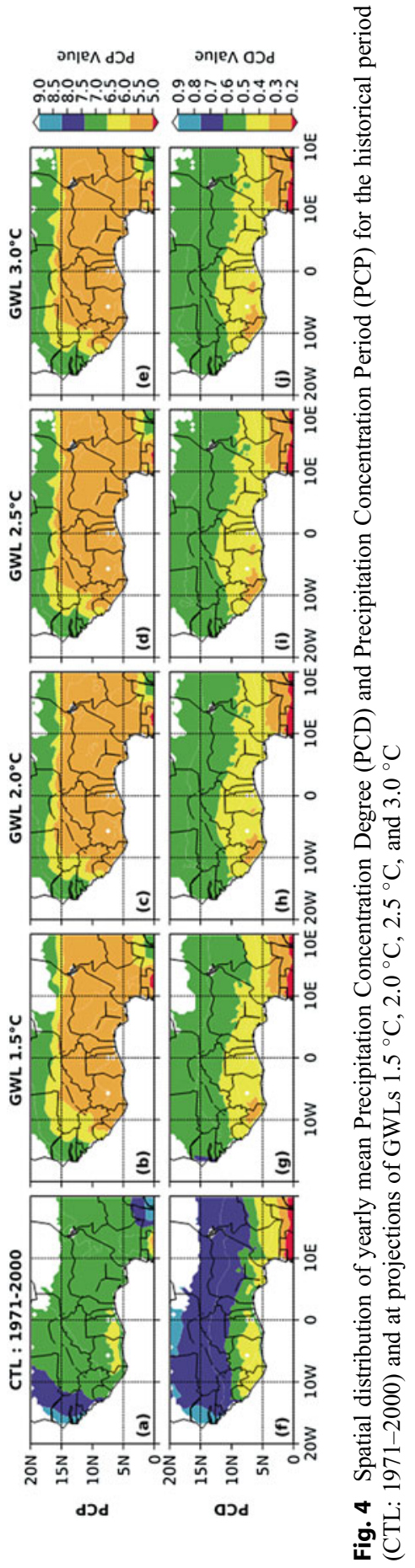


et al. 2018). Figure 5 shows the variability between the projection of different GWLs and the selected historical period. High values of CDD are noticed in the north of West Africa, and higher CWD values around the coast of Gulf of Guinea. The comparison between the results of (Figs. 5a-d, i-1) shows both for annual and rainy season periods a decrease of CDD about $10 \pm 5$ days over the north-eastern of West Africa. Around the northern area of the study domain, an important variability of dry days is noticed within the rainy season (e.g., a decrease in CDD over the north-eastern part and an increase in CDD over the north-western part), which demonstrates that the northeastern of West Africa is wetter under GWLs, while the north-western region is drier. Over the Gulf of Guinea, for both annual and rainy season scales a slight variability of CDD for all GWLs is noticed. The results of the GWLs $1.5^{\circ} \mathrm{C}, 2.0^{\circ} \mathrm{C}$, and $2.5^{\circ} \mathrm{C}$ indicate a pattern of CDD with same spatial variability, and for the GWL $3.0^{\circ} \mathrm{C}$ (on Fig. 5i), a significant increase in the annual CDD is observed. The CDD is projected to increase for 4-5 days over the Gulf of Guinea; in Mauritania and Senegal, the increase is projected to be $10 \pm 2$ days as showed by Quenum et al. (2019). Some Sahel countries like Niger and Chad (which are characterized by a dry north-easterly flow crossing the Sahara desert) are projected to record a dwindling of CDD between 10 and 14 days. This finding agrees at GWLs $1.5{ }^{\circ} \mathrm{C}$ and $2.0^{\circ} \mathrm{C}$, with Klutse et al. (2018), who showed a reduction for GWLs $1.5^{\circ} \mathrm{C}$ and $2.0^{\circ} \mathrm{C}$, in terms of the number of CDD in the wet season over our study domain, and also the results of Sultan and Gaetani (2016), who concluded a decrease in the number of CDD over central Africa.

In contrast to the CDD analysis over West Africa, the CWD did not show important variability. Its variation is very slight and ranges between $0 \pm 3$ days. Nonetheless, some high variations could be observed at several specific points. On the projected simulations illustrated in Fig. 5e-h), the CWD decreases about $10 \pm 2$ over the South Benin and Nigeria. A slight augment in CWD of up to 2 days is likely to be noticed in the Sahel.

In order to investigate the spatial variability of extreme rainfall events, which plays an important role in the availability of water resources and agriculture, etc., the frequency of intense rainfall events (RxD10 $\mathrm{mm}: R \geq 10 \mathrm{~mm} /$ day), very intense rainfall events (RxD20 mm: $R \geq 20 \mathrm{~mm} /$ day), and heavy rainfall events (RxD25 mm: $R \geq 25 \mathrm{~mm} /$ day) were calculated; they are displayed in Fig. 6 . These variables indicate whether there were changes in the amount of precipitation received over consecutive 5 days with the highest precipitation. Figure $6 \mathrm{a}-\mathrm{d}$ illustrate that, compared to the control period, each GWL detects an increasing RxD10 mm over the orographic regions and the ocean boundary (Gulf of Guinea). There is a very slight increase in the number of RxD10 mm over the Savanna and Sahel zones. In general, the results clearly show that as the GWL increases, the more the projected RxD10 mm increases too (e.g., for GWL $1.5^{\circ} \mathrm{C}$, the increase is about $7 \pm 2$ over the Gulf of Guinea and $1 \pm 1$ for the Savanna and Sahel, while for GWL $3.0^{\circ} \mathrm{C}$, the increase is about $9 \pm 2$ over the Gulf of Guinea and $3 \pm 1$ for the Savanna and Sahel). In the case of RxD20 mm and RxD25 mm, the general increase in response to increasing GWLs is noticed too. Only the coastal countries record significant increases in RxD20 mm and RxD25 mm, which could be due to the south-westerly moist flow from the Gulf of Guinea inland. 

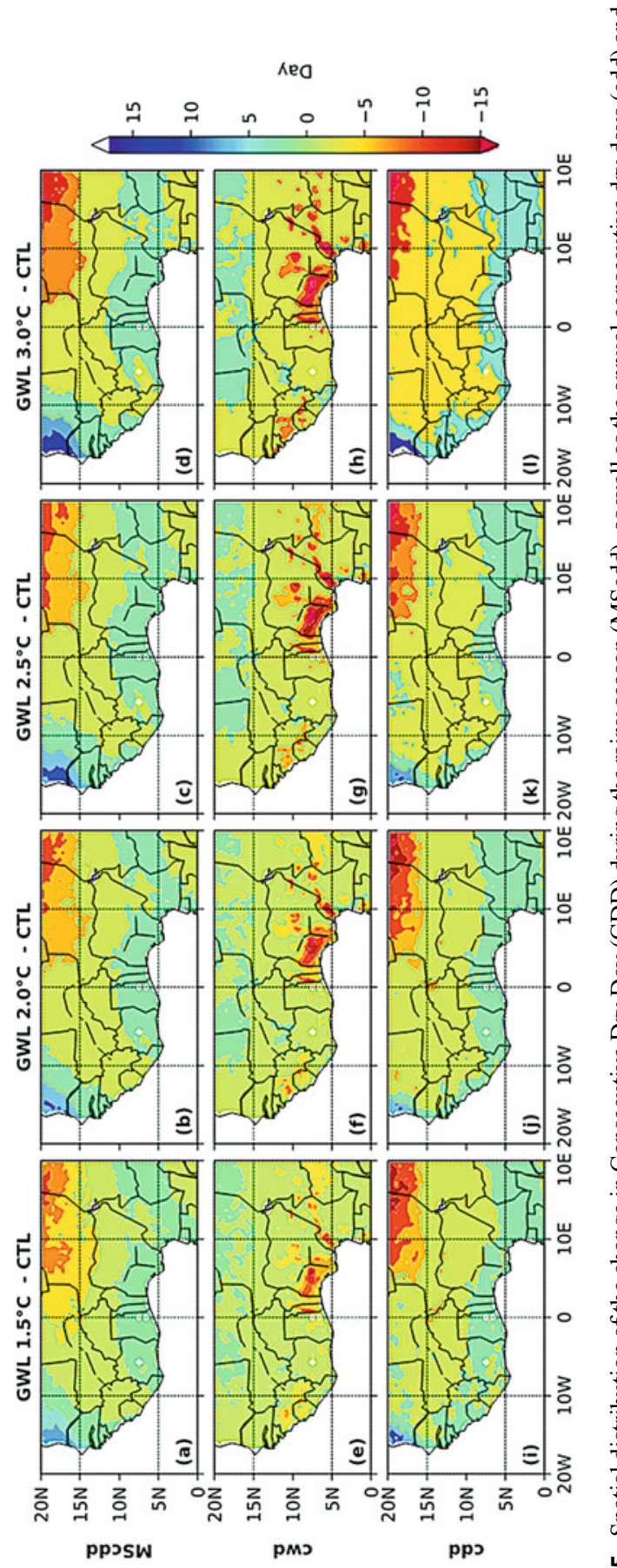

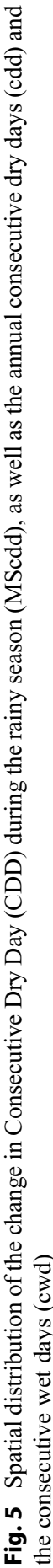




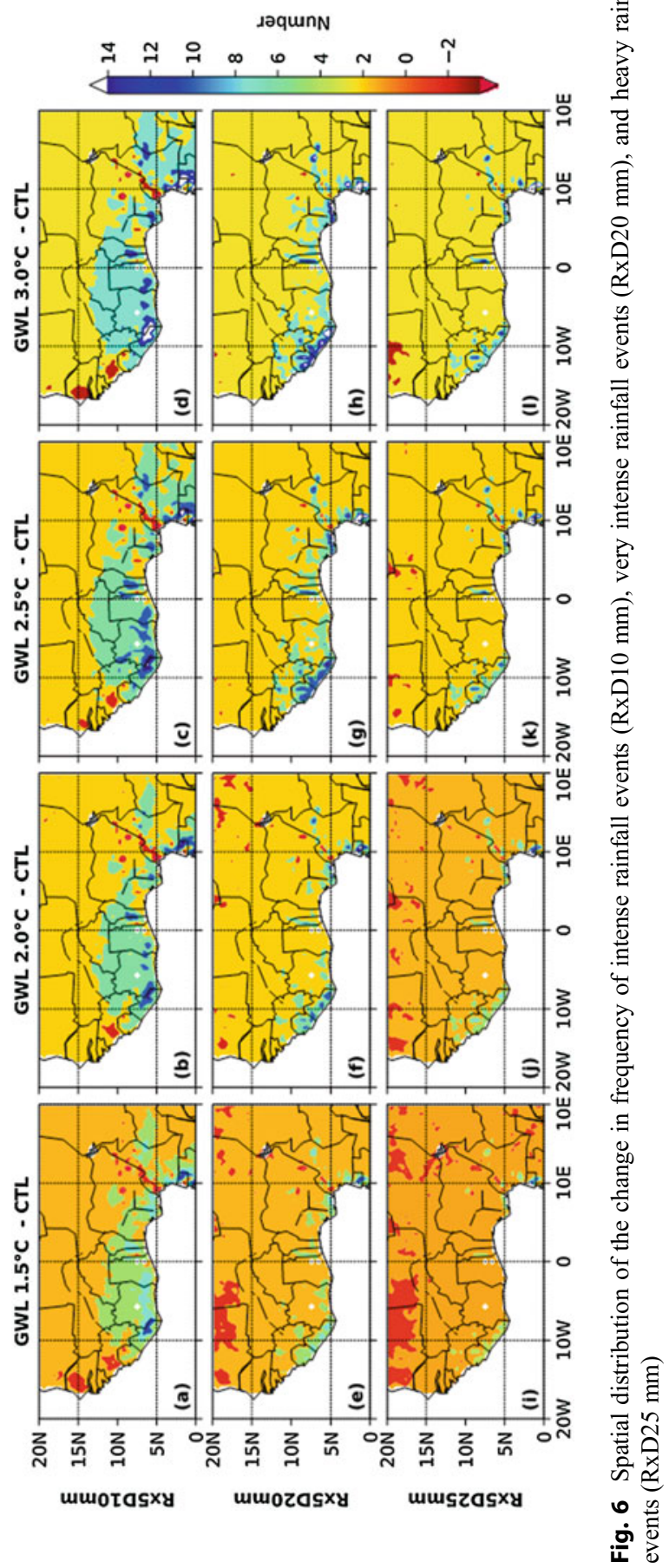




\section{Adaptation Strategies}

Since the spectacular drought events of the 1970s, it has become clear that the high variability in precipitation constitutes one of the major challenges faced by the West African region. Agriculture is one of the major economic activities of West Africa, and thus significant changes in rainfall due to climate change will negatively affect the entire region. These concerns have generated ongoing scientific, social, and political debate. Moreover, some parts of West Africa (mostly along the Guinean Coast) have recorded recurrent flood events since 2000. Thus, both climate variability and increasing trends in droughts and floods and other severe weather events pose a challenge for the primarily rain-fed agriculture systems in West Africa (Sultan and Gaetani 2016). Therefore, any adaptations must enable inhabitants to cope successfully with short-term climate variability as well as to reduce the long-term negative impacts of climate change (Lobell 2014; Saba et al. 2013). Households and communities must become accustomed to and able to respond creatively and effectively to disruptions of their livelihoods. Indeed, in order to be successful, adaptations must be anchored in all processes affecting life. Some of the possible adaptation strategies, especially relating to floods, droughts, and food crops, are illustrated in this study.

According to the results above, at increasing GWLs, precipitation over the Gulf of Guinea and the Savanna will shift and start earlier (in May) and that the highest precipitation concentration will occur in May-June over that area. In addition, intense rainfall events and consecutive wet days will increase in frequency, which can expose the Gulf of Guinea and Savanna to flood events from June onwards. This confirms the results from Donat et al. (2016), which showed that the intensification of the hydrological cycle both in recent decades and in future projections will lead to an increased risk of flooding in dry regions as the climate warms. Groundnut, cassava, and maize are important crops for the Gulf of Guinea, especially for Nigeria, southern Mali, Benin, Ivory Coast, Burkina Faso, Ghana, and Senegal, while over the Savanna, the main crops are yam, millet, and sorghum. Therefore, to inform farmers about short-term coping and adaptation practices, scientists are encouraged to simulate crop models and to assess their uncertainties according to the shift in the times of the projected precipitation distribution and the increase in the soil temperature. Alternative strategies, such as constructing infrastructure or irrigation systems, could also be used to mitigate the impact of exposure.

Regional provisions and strategies that include all West African countries should be developed to meet the challenge of combating GHG production. The framework agreements must link and bind countries to ensure strict compliance with community-based adaptation measures. At the local level, moreover, each country will have to develop precautionary flood and drought warning systems to limit the loss of human life. Scientific community frameworks need to be developed at the local level to improve the seasonal prediction of rainfall models that must be updated frequently in order to generate reliable information. Better research findings are needed to increase knowledge of how information structures could be framed and used to reduce the power of parochial conflicting benefits and overcome inertia, apathy, and lack of political drive. Finally, communication systems geared toward achieving 
specific targets (e.g., to assist farmers) will have to be developed. Informing media platforms about climate sciences and adaptation strategy policies and discussions, for instance, would educate the public about the impacts of global warming, the importance of reducing GHG emissions, and the need for developing and implementing mitigation and adaptation strategies.

\section{Discussion and Conclusion}

It is widely demonstrated in the literature that West Africa is vulnerable to climate change due to its high climate variability and high reliance on rain-fed agriculture. It does not have an institutional capacity to respond and to adapt climate variability and climate change (Quenum et al. 2019). In order to reduce risks and suggest reliable adaptation strategies for predicted climate change, this study focused on determining the variability of precipitation both in the present time and under various future scenarios. The findings obtained with regard to the PCI showed that in West Africa the period summarizing the main rainfall activity is between May and September. For the historical period, simulations show over the Gulf of Guinea and the Savanna a uniform precipitation distribution, and in the Sahel both moderate and irregular distribution of precipitation. Under future scenarios, i.e., at all the GWLs $\left(1.5^{\circ} \mathrm{C}, 2.0{ }^{\circ} \mathrm{C}, 2.5{ }^{\circ} \mathrm{C}\right.$, and $3.0{ }^{\circ} \mathrm{C}$ in this study), the magnitude of the simulated PCIs over West Africa reduced and became close to $\mathrm{PCI}<10$. This demonstrates that under the selected GWLs, the precipitation concentration of West African becomes more uniformly distributed except for some countries in the north-eastern areas (Niger and Chad), which are least dry at all four GWLs. To get further details on the temporal patterns of the precipitation concentration in the study domain, the PCP variable is computed, which reveals that the magnitude of the PCI increases northwardly materializing a south-north precipitation gradient. The highest precipitation concentrations during the control period occur in July-August and cover the Gulf of Guinea and the Savanna regions, whereas the Sahel records the peaks of its precipitation concentration in September. The PCP too changed in response to increasing GWLs. Therefore, the precipitation for the projected period becomes more concentrated in June-July over the Gulf of Guinea and the Savanna, and in August for the Sahel region. Thus, the rainfall concentration starts one month earlier in the future period compared to the historical (which is very important and needed information for the agricultural sector). Globally, it also noticed that the Savanna-Sahel region recorded a high magnitude of PCD. This means that the total yearly precipitation recorded in this region occurs in a short time, due to the WAM system, which is led by the back-and-forth movement of the Inter-Tropical Discontinuity (ITD) between south and north. Indeed, this movement creates an increased precipitation concentration in the Savanna-Sahel area, which is immediately followed by the southward movement of the ITD. This establishes a long time record of precipitation concentration, which is highlighted by the PCD values over this area. A significant reduction in the CDD is recorded over the north-east (i.e., Niger and Chad), and a slight increase in the number of CWD over the Sahel. 
Additionally, based on the results from PCI and PCP, Niger and Chad are projected to experience more wet condition under increasing GWLs. The 5-day cumulative rainfall variable shows that the Gulf of Guinea is projected to experience more intense, very intense, and heavy rainfall events under increasing GWLs. All these results together show how much West Africa will be exposed to higher variability of climate change and also to future heavier rainfall and wet conditions.

To cope with such changes, reduce loss of life, and better manage the impact on inhabitants of this region, some adaptation strategies are necessary under continual climate change. Two types of strategies are required: a regional framework agreement and local coping strategies. The regional agreement is very important because it forces each stakeholder (country) to respect the framework agreement; this is mostly in line with mitigation of climate change at the regional scale. Local strategies are important in two ways: Firstly, local strategies should enable West African countries to respect the regional framework agreement. Secondly, they should encourage countries to look for and develop adequate adaptation possibilities, by responding to the contributions of scientists and decision makers, which represent an important factor in development. They are the ones who have to provide reliable information to the population, and particularly to farmers, for better management of crops in order to ensure food security.

In summary, this study has investigated precipitation variability and change in West Africa under increasing GWLs, and identified an earlier onset of rainfall, especially over the Gulf of Guinea. It has found that the variability of CDDs and CWDs under increasing GWLs is considerable, and that even the intensity of rainfall has increased. Such significant information is useful for farmers and decision makers to ensure the survival and prosperity of the population.

Acknowledgments This work was funded by the German Federal Ministry of Education and Research (BMBF) through the West African Science Service Center on Climate Change and Adapted Land Use (WASCAL), which provided a research fund to Gandome Mayeul L.D. Quenum. The Centre for High-Performance Computing (CHPC, South Africa) provided the computing facility used for the study.

\section{References}

Abiodun BJ, Makhanya N, Petja B, Abatan AA, Oguntunde PG (2019) Future projection of droughts over major river basins in Southern Africa at specific global warming levels. Theor Appl Climatol 137(3-4):1785-1799. https://doi.org/10.1007/s00704-018-2693-0

Barron J, Rockström J, Gichuki F, Hatibu N (2003) Dry spell analysis and maize yields for two semi-arid locations in east Africa. Agric For Meteorol, Elsevier 117:23-37. https://doi.org/ 10.1016/S0168-1923(03)00037-6

Chou C, Lan C-W (2011) Changes in the annual range of precipitation under global warming. J Clim 25:222-235. https://doi.org/10.1175/JCLI-D-11-00097.1

De Luis M, González-Hidalgo JC, Brunetti M, Longares LA (2011) Precipitation concentration changes in Spain 1946-2005. Nat Hazards Earth Syst Sci 11(5):1259-1265. https://doi.org/ 10.5194/nhess-11-1259-2011 
De Perthuis C, Hallegatte S, Lecocq F (2010) Économie de l' adaptation au changement climatique. Conseil économique pour le développement durable, Ed, Paris

Déqué M, Calmanti S, Bøssing O, Dell A, Fox C, Haensler A, ... Teichmann C (2017) A multimodel climate response over tropical Africa at $+2{ }^{\circ} \mathrm{C}$. Climate Ser (Elsevier) 7:87-95. https:// doi.org/10.1016/j.cliser.2016.06.002

Diasso U, Abiodun BJ (2015) Drought modes in West Africa and how well CORDEX RCMs simulate them. Theor Appl Climatol 128(1-2):223-240. https://doi.org/10.1007/s00704-015$1705-6$

Donat MG, Lowry AL, Alexander LV, Gorman PAO, Maher N (2016) More extreme precipitation in the world' $s$ dry and wet regions. Nat Clim Chang 6(May). https://doi.org/10.1038/ NCLIMATE2941

Easterling DR, Meehl GA, Parmesan C, Changnon SA, Karl TR, Mearns LO (2000) Climate extremes: observations, modeling, and impacts. Sci Compass 289:2068-2074. https://doi.org/ 10.1126/science.289.5487.2068

Egbebiyi TS (2016) Future changes in extreme rainfall events and African easterly waves over west Africa. University of Cape Town, Cape Town

Ezenwaji EE, Nzoiwu CP, Chima GN (2017) Analysis of precipitation concentration index (PCI) for Awka Urban area. Hydrol Current Res 8(4):4-9. https://doi.org/10.4172/21577587.1000287

FAO, IFAD, WFP. (2015) The state of food insecurity in the world 2015. Meeting the 2015 international hunger targets: taking stock of uneven progress. (FAO, ed). Rome

Frich P, Alexander LV, Della-Marta P, Gleason B, Haylock M, Tank Klein AMG, Peterson T (2002) Observed coherent changes in climatic extremes during the second half of the twentieth century. Clim Res 19(3):193-212. https://doi.org/10.3354/cr019193

Füssel H-M (2007) Adaptation planning for climate change: concepts, assessment approaches, and key lessons. Sustain Sci 2:265-275. https://doi.org/10.1007/s11625-007-0032-y

Gao Y, Zhu X, Yu G, He N, Wang Q, Tian J (2014) Agricultural and forest meteorology water use efficiency threshold for terrestrial ecosystem carbon sequestration in China under afforestation. Agric For Meteorol 195-196:32-37. https://doi.org/10.1016/j.agrformet.2014.04.010

Haensler A, Saeed F, Jacob D (2013) Assessing the robustness of projected precipitation changes over central Africa on the basis of a multitude of global and regional climate projections. Clim Chang 121:349-363. https://doi.org/10.1007/s10584-013-0863-8

IPCC (2001) Climate change 2001: synthesis report. A contribution of working groups I, II, and III to the third assessment report of the integovernmental panel on climate change (eds: Watson RT, The Core Writing Team). Cambridge University Press, Cambridge/New York

IPCC (2014) Climate change 2014: synthesis report. Contribution of working groups I, II and III to the fifth assessment report of the intergovernmental panel on climate change (eds: Core Writing Team, Pachauri RK, Meyer LA). IPCC, Geneva, p 151

Klutse NAB, Ajayi V, Gbobaniyi EO, Egbebiyi TS, Kouadio K, Nkrumah F, ... Dosio A (2018) Potential impact of $1.5^{\circ} \mathrm{C}$ and $2^{\circ} \mathrm{C}$ global warming on consecutive dry and wet days over West Africa. Environ Res Lett. https://doi.org/10.1088/1748-9326/aab37b

Kpadonou RA, Adegbola PY, Tovignan SD (2012) Local knowledge and adaptation to climate change in Ouémé climate change is a major threat to sustainable development in developing countries. According to IPCC (2007), poor communities particularly in sub-Saharan Africa will be most vulnerable because. Afr Crop Sci J 20(Supplement S2-20):181-192

Kumi N, Abiodun BJ (2018) Potential impacts of $1.5^{\circ} \mathrm{C}$ and $2^{\circ} \mathrm{C}$ global warming on rainfall onset, cessation and length of rainy season in West Africa. Environ Res Lett 13(5):12-13. https://doi. org/10.1088/1748-9326/aab89e

Li X, Jiang F, Li L, Wang G (2011) Spatial and temporal variability of precipitation concentration index, concentration degree and concentration period Xinjiang, China. Int J Climatol 31 (11):1679-1693. https://doi.org/10.1002/joc.2181

Lobell DB (2014) Climate change adaptation in crop production : beware of illusions. Glob Food Sec:1-5. https://doi.org/10.1016/j.gfs.2014.05.002 
Locatelli B (2011) Synergies between adaptation and mitigation in a nutshell. CIFOR

Maúre G, Pinto I, Ndebele-Murisa M, Muthige M, Lennard C, Nikulin G, . . Nicholson SE (2018) The southern African climate under $1.5^{\circ} \mathrm{C}$ and $2^{\circ} \mathrm{C}$ of global warming as simulated by CORDEX regional climate models. Environ Res Lett 13(6):065002. https://doi.org/10.1088/ 1748-9326/aab190

Moss R, Babiker M, Brinkman S, Calvo E, Carter T, Edmonds J, . . Zurek M (2008) Towards new scenarios for analysis of emissions, climate change, impacts, and response strategies. IPCC expert meeting report. Intergovernmental Panel on Climate Change, Geneva/Noordwijkerhout

Nikulin G, Jones C, Giorgi F, Asrar G, Büchner M, Cerezo-Mota R, .. Sushama L (2012) Precipitation climatology in an ensemble of CORDEX-Africa regional climate simulations. $\mathrm{J}$ Climate 25(18):6057-6078. https://doi.org/10.1175/JCLI-D-11-00375.1

Nikulin G, Lennard C, Dosio A, Kjellström E, Chen Y, Hansler A, . . Somot S (2018) The effects of 1.5 and 2 degrees of global warming on Africa in the CORDEX ensemble. Environ Res Lett 13 (6). https://doi.org/10.1088/1748-9326/aab1b1

Oliver JE (1980) Monthly precipitation distribution: a comparative index. Prof Geogr 32(3):300 309. https://doi.org/10.1111/j.0033-0124.1980.00300.x

Orlowsky B, Seneviratne SI (2012) Global changes in extreme events: regional and seasonal dimension. Clim Chang 110:669-696. https://doi.org/10.1007/s10584-011-0122-9

Quenum GMLD, Klutse NAB, Dieng D, Laux P, Arnault J, Kodja JD, Oguntunde PG (2019) Identification of potential drought areas in West Africa under climate change and variability. Earth Syst Environ 3(3):429-444. https://doi.org/10.1007/s41748-019-00133-w

Rowhani P, Lobell DB, Linderman M, Ramankutty N (2011) Agricultural and forest meteorology climate variability and crop production in Tanzania. Agric For Meteorol 151(4):449-460. https://doi.org/10.1016/j.agrformet.2010.12.002

Saba A, Gerrard MB, Lobell DB, Saba A, Biasutti M, Gerrard MB, Lobell DB (2013) Getting ahead of the curve : supporting adaptation to long-term climate change and short-term climate variability alike. CCLR 7. Retrieved from https://scholarship.law.columbia.edu/faculty_scholar ship $/ 563$

Sheffield J, Wood EF, Chaney N, Guan K, Sadri S, Yuan X, ... Ogallo L (2014) A drought monitoring and forecasting system for sub-sahara african water resources and food security. Am Meteorol Soc 95(June), 861-882. https://doi.org/10.1175/BAMS-D-12-00124.1

Shi P, Wu M, Qu S, Jiang P, Qiao X, Chen X, ... Zhang Z (2015) Spatial distribution and temporal trends in precipitation concentration indices for the Southwest China. Water Resour Manag 29 (11):3941-3955. https://doi.org/10.1007/s11269-015-1038-3

Sultan B, Gaetani M (2016) Agriculture in West Africa in the twenty-first century: climate change and impacts scenarios, and potential for adaptation. Front Plant Sci 7(August):1-20. https://doi. org/10.3389/fpls.2016.01262

Sylla MB, Gaye AT, Jenkins GS (2012) On the fine-scale topography regulating changes in atmospheric hydrological cycle and extreme rainfall over West Africa in a regional climate model projections. Int J Geophys 2012:1. https://doi.org/10.1155/2012/981649

UNFCCC (2010) Framework convention on climate change conference of the parties report of the conference of the parties on its sixteenth session, held in Cancun from 29 November to Part Two: action taken by the conference of the parties at its sixteenth session The $\mathrm{Ca}$, (March), 1-31

Van Vuuren DP, Edmonds J, Kainuma M, Riahi K, Nakicenovic N, Smith SJ, Rose SK (2011) The representative concentration pathways : an overview. Clim Chang 109:5-31. https://doi.org/ $10.1007 / \mathrm{s} 10584-011-0148-\mathrm{Z}$

Wang X, Zhang J, Yang Z (2013) Historic water consumptions and future management strategies for Haihe River basin of Northern China. Mitig Adapt Strateg Glob Chang 20:371. https://doi. org/10.1007/s11027-013-9496-5

Watkiss P, Brown S, Christensen OB, Maule CF, Hinkel J, Jacob D, . . Nicholls R (2015) Effects of $2 \mathrm{C}$ Warming-IMPACT2C modelling results: climate change and sea-level rise from a $2 \mathrm{C}$ climate. IMPACT2C Policy Brief, 2, 36 
Wiebe K, Sulser TB, Croz DM, Rosegrant MW (2017) The effects of climate change on agriculture and food security in Africa. International Food Policy Research Institute (IFPRI), Washington, DC

Zhang L, Qian Y (2003) Annual distribution features of precipitation in china and their interannual variations. Acta Meteor Sin 17(2):146

Zhang Q, Liu CX, Gemmer M, Chen YD, Liu C (2009) Changing properties of precipitation concentration in the Pearl River basin. China:377-385. https://doi.org/10.1007/s00477-008$0225-7$

Open Access This chapter is licensed under the terms of the Creative Commons Attribution 4.0 International License (http://creativecommons.org/licenses/by/4.0/), which permits use, sharing, adaptation, distribution and reproduction in any medium or format, as long as you give appropriate credit to the original author(s) and the source, provide a link to the Creative Commons license and indicate if changes were made.

The images or other third party material in this chapter are included in the chapter's Creative Commons license, unless indicated otherwise in a credit line to the material. If material is not included in the chapter's Creative Commons license and your intended use is not permitted by statutory regulation or exceeds the permitted use, you will need to obtain permission directly from the copyright holder.

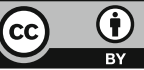

